\title{
Humor Incongruente, Efetividade da Propaganda e as Mulheres: Um Experimento no Facebook
}

\author{
Incongruent Humour, Advertising Effectiveness and Women: An Experiment On \\ Facebook
}

Luciana Ribeiro ${ }^{1}$

(iD) https://orcid.org/0000-0002-7873-9492

Martin de La Martinière Petroll ${ }^{1}$

iD https://orcid.org/0000-0001-7280-9202

Fernanda Scussel $^{1}$

https://orcid.org/0000-0001-7953-6710

Claudio Damacena ${ }^{2}$

https://orcid.org/0000-0002-8331-9302

Universidade Federal de Santa Catarina, Programa de Pós-Graduação em Administração, Florianópolis, SC, Brasil $^{1}$

Pontifícia Universidade Católica do Rio Grande do Sul, Programa de Pós-Graduação em Administração, Porto Alegre, RS, Brasil ${ }^{2}$

Artigo recebido em 16.04.2018. Última versão recebida em 10.10.2018. Aprovado em 16.11.2018. 


\title{
Resumo
}

O objetivo deste trabalho é analisar como propagandas com humor incongruente veiculadas no Facebook atuam no engajamento, nas atitudes e na intenção de compra das consumidoras brasileiras. Um experimento realizado no Facebook, com 269 consumidoras brasileiras, permitiu testar se a presença de humor incongruente influencia a efetividade das propagandas, confirmando tal hipótese, além de demonstrar que se trata de um apelo humorístico com efeitos positivos sobre o público feminino. Entre as contribuições deste artigo, destaca-se que, seus achados confirmam que engajamento, atitudes e intenção de compra conformam importantes medidas da efetividade das propagandas no contexto virtual; revelam novas facetas sobre a percepção das mulheres quanto a estímulos tradicionalmente destinados aos homens; e apontam as redes sociais como elementos fundamentais à tomada de decisão do consumidor. Evidencia-se, assim, o papel da internet como plataforma de interação entre empresas e usuários e a necessidade de construção de um relacionamento nesta conjuntura, contexto em que o humor incongruente mostra-se capaz de chamar atenção, despertar engajamento, provocar atitudes favoráveis e, deste modo, conduzir a intenção de compra.

Palavras-chave: propaganda. efetividade da propaganda. humor. humor incongruente. comportamento do consumidor.

\begin{abstract}
The objective of this paper is to analyze how ads with incongruous humor on Facebook influence female Brazilian consumer engagement, attitudes and purchase intention. An experiment conducted on Facebook with 269 women allowed us to test whether the presence of incongruous humor influences advertisement effectiveness, confirming this hypothesis, demonstrating that humorous appeal has a positive effect on female audiences. Regarding contributions, our findings confirm that engagement, attitudes and purchase intention conform to important measures of advertisement effectiveness in the virtual context; reveal new facets about women's perception of stimuli traditionally designed for men; and show social networks to be fundamental elements for consumer decision-making. Thus, we discuss the role of the Internet as a platform for interaction between companies and users and the need of building a relationship in this context, in which incongruous humor proves to be capable of catching consumer attention, arousing engagement, provoking favorable attitudes and, thereby, driving purchase intention.
\end{abstract}

Keywords: advertising; advertisement effectiveness; humor; incongruent humor; consumer behavior.

JEL code: L16, L82, M3. 


\section{Introdução}

O humor incongruente recorre a ideias contraditórias para compor uma informação inusitada, inesperada e diferente, capaz de causar surpresa e levar as pessoas ao riso (Moalla, 2015). Esse tipo de apelo humorístico é uma das técnicas mais aplicadas nas propagandas, haja vista os seus efeitos positivos na atenção e na lembrança do consumidor, além de influenciar positivamente a sua atitude (Neudecker, Esch, Schaefers, \& Valussi, 2014). Entretanto, pouca atenção é destinada ao estudo dos efeitos do humor incongruente de forma específica, conformando um ponto crucial ao desenvolvimento da pesquisa sobre o impacto das propagandas no comportamento do consumidor (Crawford \& Gregory, 2015; Hirsch, 2017; Spielmann, 2014).

A literatura é assertiva ao apontar que o humor é percebido de maneira diferente em audiências distintas (Crawford \& Gregory, 2015; Goldenberg \& Jablonski, 2011; Hirsch, 2017). Mulheres e homens percebem o humor de forma diferente: homens tendem a preferir um tipo de humor mais agressivo e com apelo sexual, enquanto mulheres preferem um humor mais leve, relacionado a emoções positivas (Aillaud \& Piolat, 2012). Ainda, evidências sugerem que as propagandas com apelo humorístico são mais bem recebidas pelo público masculino, enquanto o público feminino prefere propagandas que recorrem a apelos sentimentais (Schwarz, Hoffmann, \& Hutter, 2015). Tal panorama conduz ao primeiro questionamento deste trabalho: o humor incongruente, especificamente, funciona com o público feminino?

Em se tratando de efetividade de propaganda, é basilar considerar o contexto em que ela é veiculada (Spielmann, 2014). A internet tornou-se a principal fonte de entretenimento contemporânea, o que motivou a migração das propagandas da televisão para as redes sociais (Logan, Bright, \& Gangadharbatla, 2012). Este espaço tornou-se o principal canal de comunicação e interação entre pessoas, empresas e instituições (Kaplan \& Haelein, 2010; Nelson-Field, Riebe, \& Sharp, 2012), transformando a dinâmica entre marcas e consumidores (Lamberton \& Stephen, 2016; Silva, Demo, \& Scussel, 2017).

Neste ambiente, o Facebook ganha conotação especial pelo contexto interacional que propicia, além de ser a rede social globalmente mais popular (Al-Saggaf \& Nielsen, 2014; Logan et al., 2012) e a mais acessada no Brasil (Silva et al., 2017) - um dos cinco maiores mercados para a empresa (Oliveira, 2018). Além disso, o faturamento global do Facebook com propaganda foi de US\$11,795 bilhões no primeiro trimestre de 2018, representando $91 \%$ da receita total da empresa (Selmi, 2018).

Nas redes sociais, a interação entre marcas e usuários ocorre de forma cada vez mais rápida, exigindo das marcas a capacidade de atrair e reter a atenção dos usuários para que seja reconhecida e alvo de sua preferência (Kleineberg \& Boguñá, 2016). Neste contexto, o apelo humorístico consolidou-se como um aliado da eficiência nas propagandas (Catanescu \& Tom, 2001; Neudecker et al., 2014; Shabbir \& Thwaites, 2007), dada a sua capacidade em afetar as associações com as marcas na mente do consumidor (Strick, Holland, Baaren, \& Knippenberg, 2012).

No entanto, o humor é testado como um construto unidimensional, sem a consideração de suas três dimensões - afetiva, social e incongruente - o que pode limitar a sua compreensão (Spielmann, 2014). Em outras palavras, é preciso ir além do teste com humor e sem humor, colocando atenção nos efeitos de cada dimensão do humor sobre o comportamento do consumidor. Sabendo-se que, no Brasil, conteúdos de cunho emocional são bem recebidos pelo público, gerando avaliações positivas (Hahn, Scherer, Basso, \& Santos, 2016; Rangel, Carneiro, Oliveira, \& Monteiro, 2016), questiona-se se o humor incongruente teria a mesma resposta. Este estímulo tem impacto na efetividade das propagandas no Facebook com as consumidoras brasileiras?

Aos questionamentos supramencionados somou-se a necessidade de mensurar a efetividade das propagandas nas redes sociais (Nelson-Field et al., 2012), motivando trazer o engajamento ao debate, já que se trata de um indicador de desempenho que mede interações entre usuários e marcas (Souza, 2012). A literatura reconhece também que a propaganda no Facebook tem efeitos positivos na

RAC, Rio de Janeiro, v. 23, n. 1, art. 1, pp. 1-22, janeiro/fevereiro, 2019, http://rac.anpad.org.br (cc)E E 
avaliação do consumidor (Hahn et al., 2016) e na intenção de compra (Rangel, Carneiro, Oliveira, \& Monteiro, 2016), mas a forma como se atinge esses construtos é pouco explorada. Não se sabe os efeitos do humor na propaganda via Facebook, tampouco sobre a efetividade do humor incongruente neste contexto.

Destarte, o objetivo deste artigo consiste em analisar a influência do humor incongruente na efetividade das propagandas veiculadas no Facebook, em termos de engajamento, atitudes e intenção de compra das consumidoras brasileiras.

\section{Referencial Teórico}

A utilização do apelo humorístico na propaganda é motivada pela possibilidade de criar um momento de distração e alegria, conquistando a atenção das pessoas (Fedrizzi, 2003). Nas propagandas, configura-se uma estratégia para causar o relaxamento do público-alvo, provocando maiores assimilação e memorização da mensagem transmitida (Hegarty, 2003).

De acordo com Beard (2008), o humor é formado por três dimensões, quais sejam, dimensão afetiva, relacionada ao lado emocional dos indivíduos; dimensão social, em referência ao entendimento do humor relacionado a um contexto específico; e, por fim, o humor incongruente, relativo à capacidade de o consumidor resolver situações divertidas e confusas, nos quais sátira e sarcasmo são elementos comuns na formação do apelo.

Spielmann (2014) explica que a pesquisa sobre o apelo humorístico na propaganda, frequentemente, considera o humor como um todo, sendo pouca atenção dedicada aos efeitos de cada dimensão no comportamento do consumidor. No entanto, o avanço da pesquisa sobre humor na propaganda depende da compreensão desses efeitos, já que cada tipo de humor gera diferentes respostas do consumidor (Crawford \& Gregory, 2015; Hirsch, 2017; Spielmann, 2014). Dessa forma, este artigo une-se aos esforços em explorar as dimensões do humor de forma isolada, contribuindo com o entendimento de como diferentes tipos de humor influenciam o consumidor.

O humor incongruente é aquele que apresenta um evento que não se comporta conforme as expectativas do espectador: animais, coisas ou pessoas anunciadas na propaganda apresentam-se de forma atípica e impensada, diferente do que é normalmente esperado (Cifuentes, 2005). No humor incongruente, a emoção positiva ocorre por meio de dois estágios, a saber, a identificação da incongruência e a sua resolução, de maneira que a situação possa ser compreendida e, assim, tornar-se engraçada (Aillaud \& Piolat, 2012).

A maioria das propagandas televisivas utiliza a incongruência das expectativas para gerar humor, ou seja, recorre a situações onde algo não ocorre de acordo com as expectativas do espectador (Alden, Mukherjee, \& Hoyer, 2000). Desse modo, o humor incongruente influencia sentimentos de surpresa que, por sua vez, estão positivamente relacionados ao humor percebido. Em similitude, Krishnan e Chakravarti (2003) explicam que as mensagens mais facilmente compreendidas geram uma sensação mais intensa de aceitação da incongruência, facilitando uma resposta cognitiva mais forte, do tipo "eu entendo". Tem-se, assim, uma fonte de afeto que ajuda o consumidor a avaliar positivamente a emoção de surpresa que acontece com a incongruência (Alden et al., 2000).

Convém assinalar que diferentes tipos de humor encontram ressonância em diferentes pontos de vista da audiência, influenciando a efetividade das propagandas (Hirsch, 2017). Para Crawford e Gregory (2015), a consideração das diferenças entre consumidores é fundamental para a efetividade do humor na propaganda, já que indivíduos respondem de maneira distinta a propagandas com conteúdo congruente ou incongruente. Nesses termos, o consumidor deve perceber a incongruência para que ache a propaganda engraçada; ou seja, se a incongruência não é percebida, a propaganda não é engraçada, sendo nulo o apelo humorístico. 
Já é sabido que homens e mulheres reagem diferentemente a propagandas com humor, contexto em que expectativas, interpretação do conteúdo e processamento da informação são distintos, impondo às propagandas que visam ser efetivas a consideração das diferenças entre esses públicos (Ifezue, 2010). Sobre isso, Goldenberg e Jablonski (2011) afirmam que, culturalmente, contar piadas e dar risadas foi por muito tempo considerado um comportamento masculino, enquanto às mulheres cabia um comportamento afetivo, refletindo uma estrutura socioestrutural desigual em termos de status e poder (Goldenberg \& Jablonski, 2011).

Não obstante, ainda que as mulheres estejam se libertando cada vez mais das expectativas em relação ao comportamento feminino (Goldenberg \& Jablonski, 2011), a literatura acusa reflexos desse comportamento. De acordo com Aillaud e Piolat (2012), homens tendem a preferir um tipo de humor mais agressivo e com apelo sexual, enquanto mulheres preferem um humor mais leve, relacionado a emoções positivas. Na mesma linha, Schwarz, Hoffmann e Hutter (2015) revelaram que homens avaliam melhor propagandas que são engraçadas, enquanto mulheres respondem melhor a propagandas que recorrem a apelos sentimentais. Entretanto, a aceitação feminina de propagandas que se valem de humor incongruente segue como um tópico pouco explorado.

Outro ponto indicado por Spielmann (2014) é o contexto da propaganda: a forma através da qual o humor chega à audiência tem implicações nas reações do consumidor, influenciando principalmente sua atitude em relação ao anúncio. Neste artigo, o cenário da propaganda é o ambiente virtual, mais especificamente as redes sociais, espaço em que os usuários promovem conteúdos, compartilham informações e participam de discussões sobre os mais variados temas, transformando a comunicação entre consumidores e marcas, tornando-se um terreno propício à atração e ao engajamento de usuários (Batra \& Keller, 2016; Terra, 2010; Wolny \& Mueller, 2013).

Em sintonia com as ideias de Spielmann (2014) em investigar isoladamente cada dimensão do humor, Hirsch (2017) aponta que, nas redes sociais, os usuários compartilham piadas e conteúdos carregados de humor em diferentes plataformas, sendo que cada tipo de apelo humorístico (afetivo, social ou incongruente) possui uma linguagem própria e uma aceitação distinta entre diferentes grupos de usuários. Para a autora, a qualidade do humor está relacionada ao seu conteúdo, ao tipo de mídia em que é compartilhado e, principalmente, às características do usuário.

O Facebook é uma rede social que se destaca pelo volume de usuários cadastrados e pela oportunidade de interação dos indivíduos com amigos, colegas e empresas diariamente (Al-Saggaf \& Nielsen, 2014; Logan et al., 2012; Nelson-Field et al., 2012). Além disso, trata-se da rede social mais acessada pelos brasileiros, configurando um palco onde marcas e empresas se fazem presente na vida dos consumidores, estabelecendo com eles um diálogo capaz de chamar a atenção, gerar relacionamentos e, principalmente, obter maiores informações para conduzir suas estratégias (Silva et al., 2017). Há de se considerar, também, o boca-a-boca virtual, contexto em que curtidas, compartilhamentos e comentários em publicações aumentam o alcance e a visibilidade das marcas (Wolny \& Mueller, 2013).

No Facebook, as mulheres representam a maior parte dos usuários - 58\% (Vilaverde, 2016), além de serem a parcela da população que mais consome internet, seja pela troca de e-mails, mensagens instantâneas, blogs e compartilhamento de fotos e conteúdo (Logan et al., 2012). Ainda, as mulheres percebem o Facebook como um canal de interação em que podem compartilhar seus pensamentos, sentimentos e atividades, encontrando um ambiente de escuta e de troca (Al-Saggaf, 2011; Al-Saggaf \& Nielsen, 2014; Barker \& Ota, 2011). É plausível dizer que, no Facebook, as mulheres buscam e encontram conexão com outras pessoas.

\section{Desenvolvimento das hipóteses de pesquisa}

Frente à discussão elaborada, considerou-se contributivo analisar o comportamento do público feminino frente à propaganda sem humor e propaganda com humor incongruente. Tendo em vista que o apelo humorístico é utilizado como estratégia para causar identificação com o público, informar e entreter (Zepeda, Franco, \& Preciado, 2014) e a necessidade de compreender o efeito deste estímulo

RAC, Rio de Janeiro, v. 23, n. 1, art. 1, pp. 1-22, janeiro/fevereiro, 2019, http://rac.anpad.org.br (cc)E E 
sobre a efetividade das propagandas nas redes sociais, apresentam-se, a seguir, os aspectos do comportamento do consumidor escolhidos como medidas da efetividade das propagandas, quais sejam, engajamento, atitudes e intenção de compra.

\section{Engajamento}

O engajamento do consumidor reflete um estado psicológico decorrente da interação com a marca ou empresa (Brodie, Hollebeek, Juric, \& Ilic, 2011), abarcando, além da compra dos produtos e serviços, o boca-a-boca e as recomendações e referências dos consumidores, aspectos que são potencializados no contexto da internet, onde as percepções se espalham rapidamente (Doorn et al., 2010).

Para Brodie, Hollebeek, Juric e Ilic (2011), o engajamento no ambiente virtual pressupõe a aprendizagem sobre os produtos; o compartilhamento das informações e experiências; a defesa da marca e sua recomendação; a socialização, situação de onde surgem as atitudes; e o desenvolvimento de informações úteis às empresas. Além disso, no contexto virtual, o engajamento é considerado um indicador do desempenho do marketing (Souza, 2012), exigindo das marcas estratégias criativas para que suas propagandas engajem o consumidor via redes sociais (Ashley \& Tuten, 2015).

Nesta perspectiva, o papel das propagandas é gerar familiaridade com a marca, criar relevância e estimular o usuário a marcar amigos nas postagens e compartilhar a mensagem da marca (Stathopoulou, Borel, Christodoulides, \& West, 2017). Considerando o efeito do humor incongruente nos consumidores (Cifuentes, 2005; Kellaris \& Cline, 2007; Martin, 2007; Moalla, 2014), questiona-se se a presença deste tipo de humor tem efeito sobre o engajamento e, no presente estudo, de mulheres sobre a marca anunciada no Facebook.

Assim, com o objetivo de comparar o desempenho de engajamento na propaganda com humor incongruente em relação à propaganda sem humor e identificar se a presença de humor incongruente em uma propaganda impacta no engajamento, formulou-se a primeira hipótese do estudo:

H1: O humor incongruente inserido na propaganda veiculada no Facebook afeta positivamente no engajamento das consumidoras na forma de curtidas, compartilhamentos e comentários sobre a propaganda.

\section{Atitudes e intenção de compra}

A literatura sinaliza a relação entre as atitudes e as intenções comportamentais do consumidor: Garcia e Santos (2011) concluíram que as características pessoais dos indivíduos afetam sua atitude sobre compras na internet, construto que acaba por influenciar a intenção de compra no ambiente virtual. Já Araújo e Loureiro (2014) indicam que há relação positiva entre atitude e intenção de compra, enquanto Borges, Carvalho e Miranda (2016) apontam que a atitude pode ser considerada um antecedente da intenção de compra. Trazendo atitude e intenção para o contexto deste estudo, questiona-se se o humor incongruente influencia tais construtos, motivo pelo qual se construiu a seguinte hipótese:

H2: O humor incongruente inserido na propaganda veiculada no Facebook afeta positivamente as atitudes do consumidor e sua intenção de compra.

Esta segunda hipótese foi desmembrada em três outras hipóteses, de maneira a conhecer especificamente o efeito do humor incongruente nas atitudes em relação à propaganda e à empresa anunciante e, por fim, sobre a intenção de compra. 


\section{Atitudes sobre a propaganda e sobre a empresa anunciante}

Na propaganda, atitude é o sentimento positivo ou negativo do consumidor para a qual se destina a propaganda, baseada no julgamento em relação à marca ou objeto veiculado na propaganda (Fazio, Chen, McDonel, \& Sherman, 1982). A relação entre humor e atitude em relação à propaganda é amplamente discutida na literatura (Lyttle, 2001; Ray \& Batra, 1983; Zhang, 1996), sendo também comprovada no contexto das redes sociais: as mensagens do Facebook consideradas divertidas têm impacto positivo sobre as atitudes dos consumidores em relação à marca (Carrillat, D'Astous, \& Grégoire, 2014). Ainda, as propagandas no Facebook geram reações emocionais que influenciam de forma positiva a avaliação das marcas e da propaganda em si, com base na confiança despertada no consumidor (Hahn et al., 2016).

No caso do humor incongruente, quando os indivíduos são expostos à resolução de uma incongruência e são capazes de compreender o humor nela contido, há maior predisposição a atitudes positivas em relação à propaganda (Alden, Hoyer, \& Lee, 1993). A resolução do problema junto à sátira é reconhecida como engraçado pelo consumidor e, por isso, percebida de forma mais positiva (Spielmann, 2014). Assim, o humor incongruente conduz a atenção do consumidor, tendo efeito positivo na formação da atitude (Neudecker et al., 2014). Sabendo que homens e mulheres têm percepções distintas do humor, estabelece-se a seguinte hipótese:

H2a: O humor incongruente inserido na propaganda veiculada no Facebook afeta positivamente a atitude da consumidora sobre a propaganda.

De acordo com Strick, Holland, Baaren e Knippenberg (2012), a presença de humor na propaganda ajuda a quebrar a resistência do consumidor em relação a uma marca/empresa desconhecida, além de ser capaz de reduzir associações negativas do consumidor sobre determinada marca/empresa.

É plausível dizer, recorrendo-se a Spielmann (2014), que as atitudes em relação a uma propaganda influenciam as atitudes que o consumidor desenvolve em relação ao contexto da propaganda. Em outras palavras, o tipo de humor presente na propaganda, além de formar a atitude em relação a ela, também contribui para a formação da atitude em relação à marca ou empresa da propaganda veiculada.

Na mesma linha, a compreensão da incongruência na propaganda faz com que o consumidor tenha uma atitude favorável à propaganda, o que implica uma atitude favorável em relação ao produto ou à marca. Questiona-se, então, se isto valeria especificamente para o público feminino. Por tudo isso, elaborou-se a próxima hipótese do estudo:

H2b: O humor incongruente inserido na propaganda veiculada no Facebook afeta positivamente a atitude da consumidora sobre a empresa anunciante.

\section{Intenção de compra}

A conexão entre usuários e marcas propiciada pelo Facebook cria oportunidades de visibilidade e reconhecimento das marcas, facilita a participação do público, aumenta o boca-a-boca virtual e, desta forma, influencia a intenção de compra dos consumidores (Dehghani \& Tumer, 2015; Duffett, 2015). Isso porque, segundo Gunawan e Huarng (2015), as propagandas veiculadas nas mídias sociais despertam curiosidade, ajudam a criar confiança em produtos e marcas, contribuindo para sua intenção de compra. Entretanto, pouco se sabe sobre como as intenções do consumidor se formam no contexto virtual, especialmente no que tange à pesquisa sobre seus antecedentes (Bues, Steiner, Stafflage, \& Krafft, 2017).

Sabendo que o humor configura uma ferramenta que afeta positivamente a intenção de compra (Lyttle, 2001; Smith \& Sherman, 1993) e, apoiado na necessidade de explorar as dimensões do humor de forma isolada (Spielmann, 2014), interroga-se sobre a influência do humor incongruente na 
intenção de compra nas mulheres no Facebook. Ademais, no Brasil, evidências indicam que a interação no Facebook tem efeito na intenção de compra dos usuários, motivada pela reputação das marcas e pelas recomendações de outros usuários, que aumentam o valor percebido dos produtos e reduzem a percepção de risco (Rangel et al., 2016).

Assim, para verificar a intenção de compra do público feminino em relação às propagandas com apelo de humor incongruente, determinou-se a seguinte hipótese:

H2c: O humor incongruente inserido na propaganda veiculada no Facebook afeta positivamente a intenção de compra da consumidora.

\section{Procedimentos Metodológicos}

Esta seção relata os procedimentos adotados na consecução de uma pesquisa conclusiva causal, a partir de um experimento realizado no próprio Facebook, testando a presença (grupo experimental) versus ausência de humor incongruente (grupo de controle) na propaganda de uma marca fictícia criada exclusivamente para a pesquisa. A criação de propagandas para uma pesquisa traz a vantagem de o consumidor não estar familiarizado com as marcas (Alexander \& Judd, 1978). Há também a vantagem de extrair os efeitos de humor sobre a propaganda e a empresa sem incorporar possíveis fatores de confusão, como prévio conhecimento e experiência com uma marca madura (Simpson, Horton, \& Brown, 1996).

A criação da propaganda fictícia envolveu um pré-teste com dez mulheres escolhidas por conveniência, que selecionaram, entre quatro opções, a imagem que consideraram mais engraçada e incongruente. Neste caso, a variável independente foi o humor incongruente na propaganda, na forma de dois anúncios: um com o apelo de humor incongruente para o grupo experimental, mostrando uma tatuagem de um tigre em uma das pernas de uma mulher sendo depilada com uma lâmina de depilação feminina; e um sem apelo humorístico, mostrando uma imagem de uma perna de uma mulher sendo depilada com uma lâmina de depilação feminina, desta vez sem tatuagem. Ambos os anúncios continham a mesma marca fictícia (Outex), na mesma posição (canto inferior esquerdo) e de mesmo tamanho. Com relação às quatro variáveis dependentes do presente estudo, estas são: (a) engajamento; (b) atitudes sobre a propaganda; (c) atitudes sobre a empresa anunciante; e (d) a intenção de compra do produto anunciado.

Seguindo as orientações de Patino, Pitta e Quinones (2012), a análise do engajamento deu-se pela observação e análise dos comentários, bem como pela comparação no número de curtidas e compartilhamentos nos dois tipos de propaganda, com humor incongruente e o sem humor. Registrase que o Facebook disponibiliza um aplicativo gerenciador de anúncios, usado neste estudo, onde é possível acompanhar quantas pessoas curtem a página e a quantidade de novas curtidas; quantas pessoas viram a página e suas publicações; e quantas pessoas clicaram, curtiram, comentaram ou compartilharam a página ou publicações.

Em relação à mensuração da atitude sobre a propaganda, da atitude sobre a empresa anunciante e da intenção de compra, elaborou-se uma adaptação do questionário de Petroll (2007) e de Petroll e Rossi (2008), formado por 19 itens apresentados em uma escala de diferencial semântico de sete pontos. Estes itens foram originalmente apresentados em estudos de Henthorne e LaTour (1995), LaTour e Henthorne (1993, 1994) e de Simpson, Horton e Brown (1996) para mensurar a atitude sobre a propaganda; de Mackenzie e Lutz (1989) e de Simpson et al. (1996) para mensurar a atitude sobre a empresa anunciante e, finalmente, de Simpson et al. (1996) para mensurar a intenção de compra. A composição da versão de aplicação do questionário é apresentada pela Tabela 1. 
Tabela 1

\section{Itens do Questionário}

\begin{tabular}{|c|c|c|}
\hline Variável & Número de Itens & Descrição dos Itens \\
\hline \multirow{12}{*}{$\begin{array}{l}\text { Atitude em relação à } \\
\text { propaganda }\end{array}$} & \multirow[t]{12}{*}{12} & Sou favorável - Sou desfavorável \\
\hline & & Não gosto - Gosto \\
\hline & & Me sinto bem - Não me sinto bem \\
\hline & & É ruim - É boa \\
\hline & & É diferente - Não é diferente \\
\hline & & É irritante - Não é irritante \\
\hline & & É informativa - Não é informativa \\
\hline & & É ofensiva - Não é ofensiva \\
\hline & & É de alta qualidade - É de baixa qualidade \\
\hline & & É desinteressante - É interessante \\
\hline & & É apropriada - É inapropriada \\
\hline & & Não me atrai - Me atrai \\
\hline \multirow{4}{*}{$\begin{array}{l}\text { Atitude em relação à } \\
\text { empresa anunciante }\end{array}$} & \multirow[t]{4}{*}{4} & Deve ter ótima reputação - Deve ter péssima reputação \\
\hline & & Sou desfavorável a ela - Sou favorável a ela \\
\hline & & Deve ser uma boa empresa - Deve ser uma má empresa \\
\hline & & $\begin{array}{l}\text { Deve ser uma empresa desagradável - Deve ser uma empresa } \\
\text { agradável }\end{array}$ \\
\hline \multirow[t]{3}{*}{ Intenção de compra } & \multirow[t]{3}{*}{3} & Provável - Improvável \\
\hline & & Gostaria - Não gostaria \\
\hline & & Possível - Impossível \\
\hline
\end{tabular}

Nota. Fonte: Adaptado de Petroll, M. M. (2007) Apelo sexual na propaganda: um experimento em mídia impressa (Dissertação de mestrado). Universidade Federal do Rio Grande do Sul, Porto Alegre, RS, Brasil; Petroll, M. M., \& Rossi, C. A. V. (2008). Apelo sexual na propaganda e seus efeitos sobre o consumidor: Um experimento em mídia impressa. Revista de Administração $\quad$ Eletrônica, $\quad 1(2), \quad 1-22 . \quad$ Recuperado de https://www.researchgate.net/profile/Carlos_Rossi5/publication/266875892_Apelo_sexual_na_propaganda_e_seus_efeitos_s obre_o_consumidor_um_experimento_em_midia_impressa/links/54b665b20cf24eb34f6d159a/Apelo-sexual-na-propagandae-seus-efeitos-sobre-o-consumidor-um-experimento-em-midia-impressa.pdf

As propagandas e marca criadas para o estudo foram inseridas no Facebook com investimento de $R$ \$ 175,00 (cada propaganda) para garantir a exposição de ambas para a mesma quantidade de mulheres, sendo que as propagandas só poderiam ser expostas para mulheres brasileiras com mais de 18 anos que tivessem uma conta no Facebook. Optou-se por inserir a propaganda no feed de notícias com o intuito de imitar uma publicação comum, estimulando as curtidas, comentários e compartilhamentos, já que não foi informado às mulheres expostas às imagens que a propaganda era referente a um estudo científico.

O questionário foi enviado apenas para aquelas que interagiram com a propaganda por meio de curtidas na publicação, comentários ou compartilhamentos, totalizando 722 mulheres, sendo 410 referentes à propaganda com humor e 312 à propaganda sem humor. Dessas, 278 responderam ao questionário da pesquisa - 150 para a propaganda com humor e 128 para a propaganda sem humor. 
As respostas obtidas foram exportadas para o software IBM SPSS® Statistics 23 para a etapa de tratamento dos dados. Não houve nenhum questionário excluído por dados faltantes. Na identificação de outliers, utilizou-se a detecção multivariada com a medida $\mathrm{D}^{2}$ de Mahalanobis, excluindo-se seis observações atípicas no grupo de mulheres exposto à propaganda com humor incongruente e três observações atípicas no grupo de mulheres exposto à propaganda sem humor. Ao final desta etapa, a amostra contou com 269 questionários válidos, sendo 144 referentes à propaganda com humor e 125 à propaganda sem humor. A amostra é formada majoritariamente por mulheres de até 30 anos e que possuem o Ensino Médio ou Superior.

Para os testes de hipóteses foram utilizadas as seguintes técnicas estatísticas: qui-quadrado e Manova. O qui-quadrado foi utilizado na hipótese 1 e nas hipóteses restantes a Manova. É importante destacar que antes da utilização da Manova, as escalas foram avaliadas quanto a sua confiabilidade, validade convergente e discriminante com o software SPSS (para o cálculo do alfa de Cronbach) e do AMOS (para o cálculo das cargas fatoriais e das variâncias compartilhadas). Essa avaliação foi primordial para que as escalas pudessem ser transformadas, através do cálculo das médias dos itens, em variáveis únicas, o que permitiu o uso posterior dessas novas variáveis na Manova.

\section{Apresentação e Discussão dos Resultados}

Para a análise dos efeitos do humor incongruente sobre o engajamento (Hipótese 1), considerouse a forma como as participantes interagiram com os anúncios em termos das curtidas, comentários e compartilhamento.

A propaganda elaborada com humor incongruente apareceu para 99.093 mulheres e recebeu 295 compartilhamentos, foi curtida 823 vezes, marcada como Haha por 252 mulheres, classificada como amei por mais 129, ainda recebeu 11 comentários e duas respostas a comentários. Já a propaganda sem humor apareceu no feed de notícias de 90.388 mulheres, foi compartilhada três vezes, curtida 282 vezes, marcada como Amei por 28 mulheres e recebeu três comentários.

Com base nos testes estatísticos expostos na Tabela 2, retornou-se à Hipótese 1, segundo a qual há diferenças entre o efeito da presença ou ausência do humor incongruente no engajamento do consumidor. Os resultados indicam que os anúncios com humor incongruente geraram mais engajamento com o público, o que permite aceitar a hipótese $\mathrm{H1}$ e afirmar que o humor incongruente impacta positivamente o engajamento da consumidora na forma de curtidas, compartilhamentos e comentários sobre a propaganda.

Tabela 2

\section{Frequência e Testes Qui-quadrado para as Interações dos Grupos Com e Sem Humor Incongruente}

\begin{tabular}{|c|c|c|c|c|c|}
\hline & Com Humor & Sem humor & Sem humor Amostra corrigida* & $\chi^{2}$ & Signicância \\
\hline Curtidas & 823 & 282 & 310 & 232,28 & $\mathrm{P}<0,001$ \\
\hline Marcadas (Haha ou amei) & 381 & 28 & 31 & 297,33 & $\mathrm{P}<0,001$ \\
\hline Compartilhamentos & 295 & 3 & 3 & 286,12 & $\mathrm{P}<0,001$ \\
\hline Comentários & 11 & 3 & 3 & 4,57 & $\mathrm{p}<0,05$ \\
\hline Total & 1510 & 316 & 348 & 726,72 & $\mathrm{P}<0,001$ \\
\hline
\end{tabular}

Nota. A amostra foi corrigida em função de número menor de exposições da propaganda sem humor. Por exemplo, o valor 310 foi obtido pelo seguinte cálculo: 99.000x282/90.000. Fonte: dados da pesquisa. 
A literatura aponta que as redes sociais permitem que seus usuários participem, contribuam, promovam, propaguem, opinem e discutam conteúdo e informação de maneira bilateral (Terra, 2010), de maneira muito rápida (Doorn et al., 2010). Ainda, o engajamento é traduzido na forma de compartilhamentos e recomendações (Brodie et al., 2011), contexto em que o papel das propagandas é despertar curiosidade no usuário, além do desejo de mostrar a outros o que viu (Stathopoulou et al., 2017).

Admite-se, então, que quanto mais as pessoas curtem, comentam e compartilham as propagandas que chamam sua atenção na internet, mais engajadas elas estão. Posto isto, a mensagem publicitária criada com o intuito de se tornar viral devem ser divertidas e inusitadas, fazendo com que os usuários queiram compartilhá-la (Ashley \& Tuten, 2015; Stathopoulou et al., 2017), exatamente o que foi percebido no anúncio com humor, por meio de um maior número de compartilhamentos da mensagem.

Em seguida, tem-se o teste dos efeitos do humor incongruente nas atitudes sobre a propaganda, atitudes sobre a empresa patrocinadora e sobre as intenções de comportamento, em referência às hipóteses H2, H2a, H2b e H2c.

Neste caso, os itens que compunham cada construto (variáveis dependentes), deveriam passar por uma agregação, ou seja, deveriam ser calculadas as médias dos itens para cada construto. À vista disso, as novas variáveis foram utilizadas em uma Manova para testar as hipóteses. Entretanto, antes da realização desse processo de agregação dos itens, foi necessário verificar se as escalas eram confiáveis e válidas, resultados que se encontram na Tabela 3.

Tabela 3

Médias e Cargas dos Itens, e Alfa de Cronbach, Confiabilidade Composta e Variância Extraída Média dos Construtos

\begin{tabular}{|c|c|c|c|c|c|c|c|}
\hline Construto & & Item & Média & Carga & $\alpha$ & $\mathbf{C C}$ & AVE \\
\hline \multirow{12}{*}{$\begin{array}{l}\text { Atitude em } \\
\text { relação à } \\
\text { propaganda }\end{array}$} & 1 & Sou Favorável - Sou Desfavorável; (R) & 6,55 & 0,769 & \multirow{12}{*}{0,81} & 0,89 & \multirow[t]{12}{*}{0,54} \\
\hline & 2 & Não Gosto - Gosto; & 6,34 & 0,922 & & & \\
\hline & 3 & Me sinto bem - Não me sinto bem;; (R) & 6,53 & 0,684 & & & \\
\hline & 4 & É ruim -É boa; & 6,2 & 0,684 & & & \\
\hline & 5 & É diferente - Não é diferente;; (R) & 4,33 & 0,58 & & & \\
\hline & 6 & É irritante - Não é irritante; & $\underline{6,83}$ & & & & \\
\hline & 7 & É informativa - Não é informativa; (R) & $\underline{4,87}$ & & & & \\
\hline & 8 & $\underline{\text { É ofensiva - Não é ofensiva; }}$ & $\underline{6,55}$ & & & & \\
\hline & 9 & É de alta qualidade - É de baixa qualidade; (R) & 4,97 & & & & \\
\hline & 10 & É desinteressante -É interessante; & 6,27 & 0,791 & & & \\
\hline & 11 & É apropriada - É inapropriada; (R) & 6,35 & & & & \\
\hline & 12 & Não me atrai - Me atrai. & 6,03 & 0,677 & & & \\
\hline \multirow{4}{*}{$\begin{array}{l}\text { Atitude em } \\
\text { relação à } \\
\text { empresa } \\
\text { anunciante }\end{array}$} & 1 & Deve ter ótima reputação - Deve ter péssima reputação; & 6,14 & 0,514 & \multirow{4}{*}{0,66} & 0,87 & \multirow[t]{4}{*}{0,7} \\
\hline & 2 & Sou desfavorável a ela - Sou favorável a ela; & 5,77 & 0,935 & & & \\
\hline & 3 & Deve ser uma boa empresa - Deve ser uma má empresa; & 6,07 & & & & \\
\hline & 4 & $\begin{array}{l}\text { Deve ser uma empresa desagradável - Deve ser uma } \\
\text { empresa agradável. }\end{array}$ & 5,8 & 0,978 & & & \\
\hline \multirow{3}{*}{$\begin{array}{l}\text { Intenção de } \\
\text { compra }\end{array}$} & 1 & Provável - Improvável; & 6,55 & 0,891 & \multirow[t]{3}{*}{0,81} & 0,89 & \multirow[t]{3}{*}{0,61} \\
\hline & 2 & Gostaria - Não gostaria; & 6,25 & 0,653 & & & \\
\hline & 3 & Possível - Impossível. & 6,51 & 0,936 & & & \\
\hline
\end{tabular}

Nota. (R): afirmações negativas e que foram revertidas. Fonte: dados da pesquisa.

RAC, Rio de Janeiro, v. 23, n. 1, art. 1, pp. 1-22, janeiro/fevereiro, 2019, http://rac.anpad.org.br (cc) EY 
Primeiramente, os itens com afirmações negativas foram revertidos (destacadas na Tabela 3) com a letra $\mathbf{R}$ entre parênteses). Através de uma análise de Modelagem de Equações Estruturais, foram obtidos os indicadores de confiabilidade e validade do modelo composto pelos três construtos. Para obter a completa validade convergente, alguns itens foram excluídos. Esses itens excluídos podem ser visualizados na Tabela 3, sem a informação da carga e sublinhados. Por exemplo, o item 6 (É irritante - Não é irritante) do construto Atitude em Relação à Propaganda é reverso e foi excluído por apresentar carga baixa.

Ainda na Tabela 3, verifica-se que as cargas dos itens retidos, os altos valores do Alfa de Cronbach $(\alpha)$, os altos indicadores da Confiabilidade Composta (CC) e os valores da variância extraída média (Average Variance Extracted [AVE]) acima de 0,5 demonstram que os construtos e suas escalas são confiáveis e possuem validade convergente.

A Tabela 4, de forma complementar, mostra a validade discriminante das escalas e construtos. $\mathrm{Na}$ diagonal são apresentados os valores da AVE que devem ser superiores aos valores apresentados na parte inferior da Tabela 4, que são as variâncias compartilhadas entre os construtos (correlações elevadas ao quadrado). Esses resultados permitiram que fosse dado o próximo passo: o cálculo das médias dos itens retidos para cada construto e que foram usados na MANOVA no teste de hipóteses.

Tabela 4

Variância Extraída Média e Compartilhada dos Construtos

\begin{tabular}{lccc}
\cline { 2 - 4 } & $\begin{array}{c}\text { Atitude em relação à } \\
\text { propaganda }\end{array}$ & $\begin{array}{c}\text { Atitude em relação à } \\
\text { empresa anunciante }\end{array}$ & $\begin{array}{c}\text { Intenção de } \\
\text { comportamento }\end{array}$ \\
\hline Atitude em relação à propaganda & 0,54 & & \\
\hline Atitude em relação à empresa anunciante & 0,41 & 0,7 & 0,61 \\
\hline Intenção de comportamento & 0,39 & 0,14 & \\
\hline
\end{tabular}

Nota. Fonte: dados da pesquisa.

Para o teste das hipóteses, recorreu-se à técnica estatística chamada Manova. A diferença entre o teste t, Anova e Manova é que, enquanto no teste t e Anova apenas uma variável dependente é testada quanto à igualdade ao longo dos grupos, na Manova uma variável estatística é testada quanto à sua igualdade. Essa "variável estatística combina de forma ótima as múltiplas medidas dependentes em um único valor que maximiza as diferenças ao longo dos grupos" (Hair, Black, Babin, Anderson, \& Tatham, 2009, p. 309).

O resultado da Manova mostra que todas as hipóteses são significativas. A Tabela 5 apresenta os resultados do teste da Hipótese 2 e as hipóteses dela derivadas. Todas as medidas multivariadas são significativas. Confirmam, portanto, que os vetores das médias dos dois grupos não são iguais, ou seja, a presença da propaganda incongruente impacta positivamente as atitudes das participantes do experimento em relação à propaganda, suas atitudes em relação à empresa patrocinadora e, finalmente, sua intenção de compra.

Tabela 5

\section{Resultados dos Testes Multivariados da Manova}

\begin{tabular}{llllll}
\hline Efeito & Valor & F & Graus de liberdade $(\mathbf{d F})$ & Erro (dF) & Sig. \\
\hline Pillai's Trace & 0,713 & 219,727 & 3 & 265 & 0,000 \\
\hline Wilks' Lambda & 0,287 & 219,727 & 3 & 265 & 0,000 \\
\hline Hotelling's Trace & 2,487 & 219,727 & 3 & 265 & 0,000 \\
\hline Roy'sLargest Root & 2,487 & 219,727 & 3 & 265 & 0,000 \\
\hline
\end{tabular}

Nota. Fonte: dados da pesquisa.

RAC, Rio de Janeiro, v. 23, n. 1, art. 1, pp. 1-22, janeiro/fevereiro, 2019, http://rac.anpad.org.br (oc) E 
A hipótese $\mathrm{H} 2 \mathrm{a}$ questiona se há diferenças entre a presença de humor incongruente versus ausência de humor em uma propaganda e a variável dependente atitude do consumidor sobre a propaganda. Os resultados $(\mathrm{F}=605,985, \mathrm{p}<0,001)$, conforme Tabela 6, e as Figuras 1 e 2, indicaram que as participantes que observaram a propaganda com humor incongruente obtiveram atitudes mais favoráveis à propaganda $(\mathrm{M}=6,80 ; \mathrm{DP}=0,36)$ quando comparadas às que avaliaram a propaganda sem humor (M=5,16; $\mathrm{DP}=0,69)$. Desse modo, a hipótese H2a foi aceita.

Tabela 6

\section{Resultados Univariados da Manova}

\begin{tabular}{lcccc}
\hline Variável dependente & $\begin{array}{c}\text { Graus de liberdade } \\
(\mathbf{d F})\end{array}$ & Média Quadrática & F & Sig. \\
\hline Atitude em relação à propaganda & 1 & 178,267 & 605,99 & 0,000 \\
\hline Atitude em relação à empresa patrocinadora & 1 & 26,036 & 32,884 & 0,000 \\
\hline Intenção de comportamento & 1 & 39,947 & 125,4 & 0,000 \\
\hline
\end{tabular}

Nota. Fonte: dados da pesquisa.

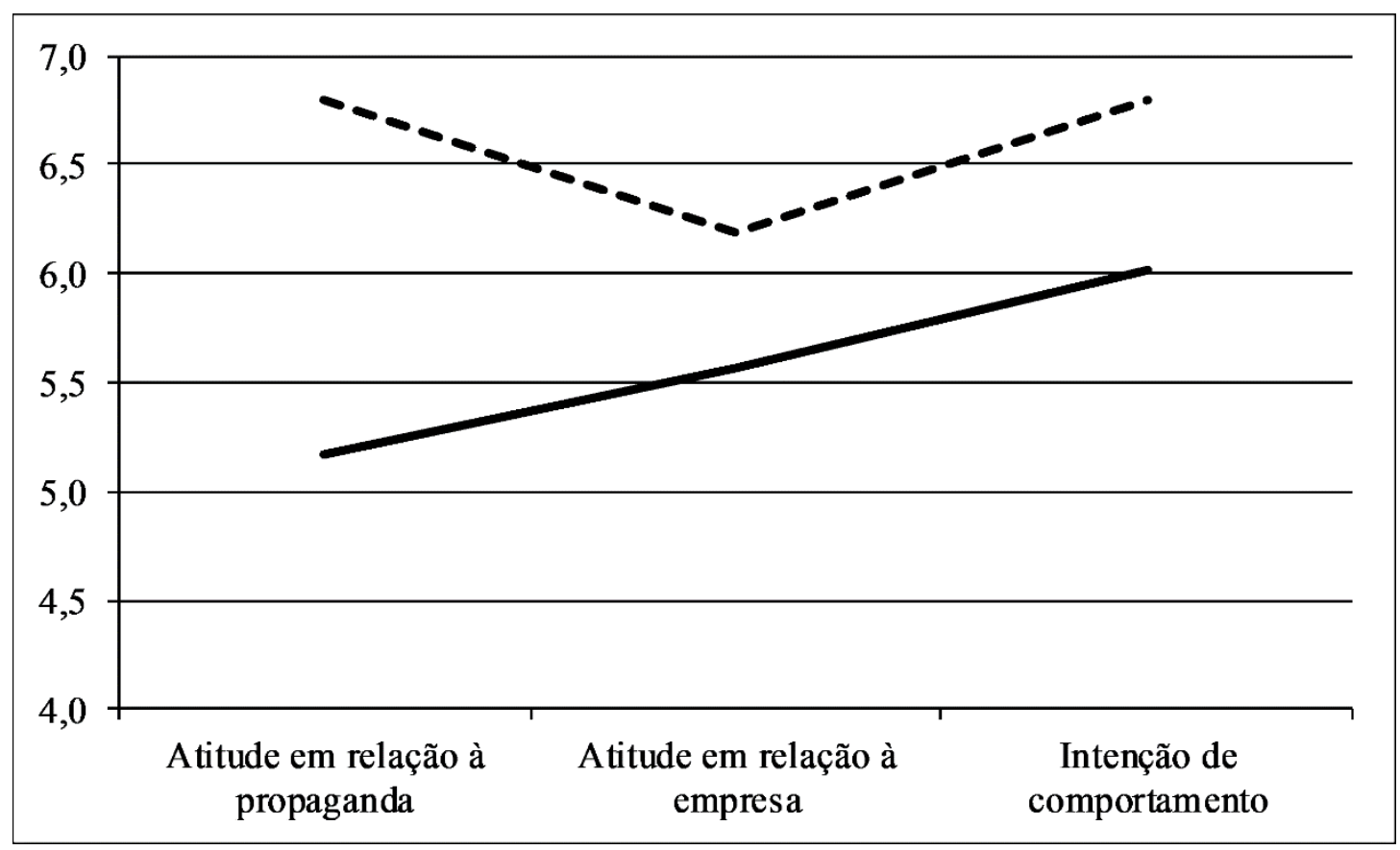

Com humor incongruente - . - -

Sem humor

Figura 1. Médias das Atitudes em Relação ao Humor Incongruente (e sem Humor) na Propaganda, à Empresa e na Intenção de Compra 
Fonte: Dados da pesquisa.

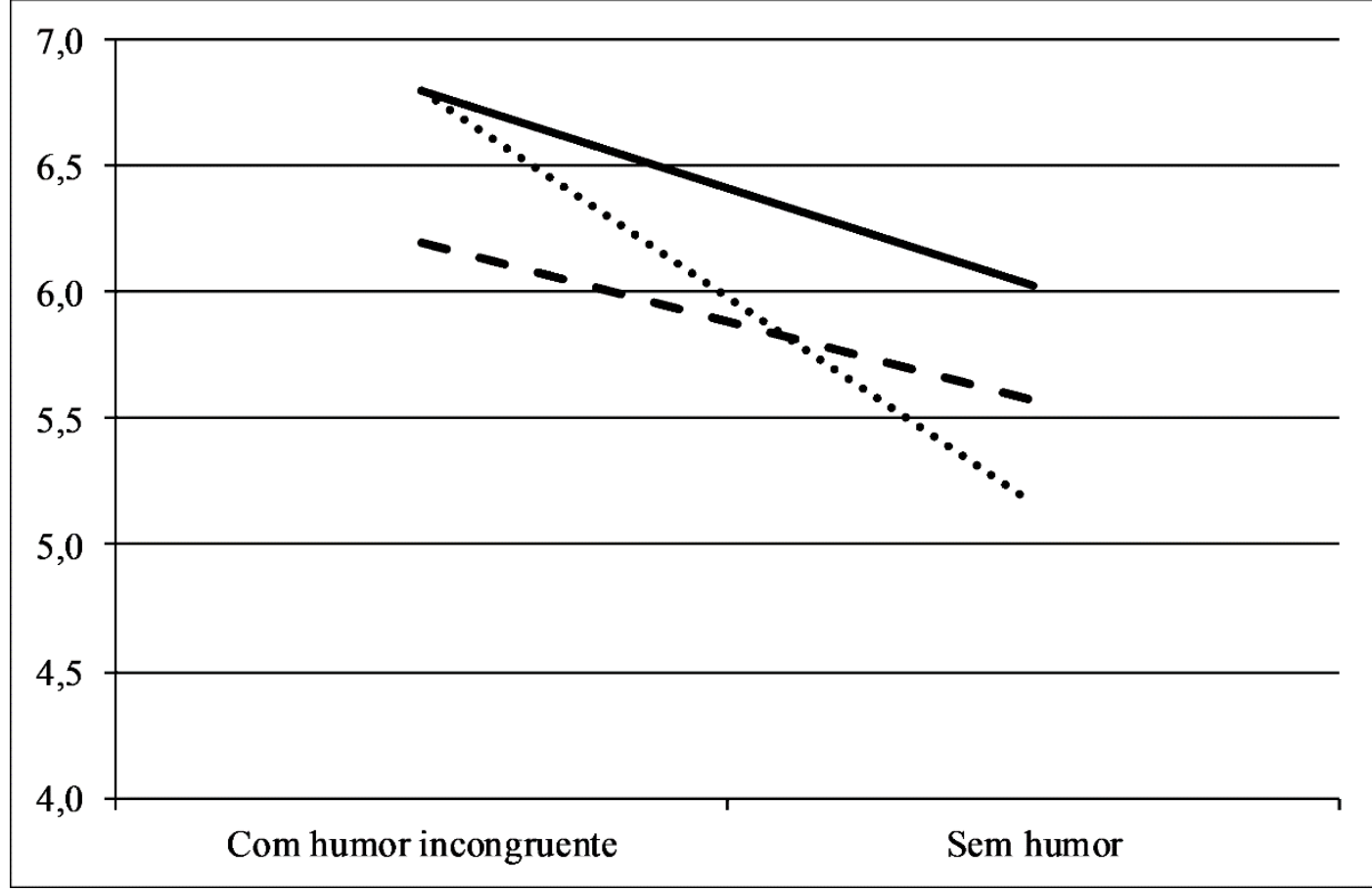

Atitude em relação à propaganda •••••••••

Atitude em relação à empresa - - - -

Intenção de comportamento

Figura 2. Médias das Atitudes em Relação ao Humor Incongruente (e Sem Humor) na Propaganda, À Empresa e na Intenção de Compra

Fonte: dados da pesquisa.

Já segundo a hipótese $\mathrm{H} 2 \mathrm{~b}$, os resultados ( $\mathrm{F}=32,884, \mathrm{p}<0,001)$, expostos na Tabela 6 e Figuras 1 e 2, também mostram que há diferenças entre a presença de humor incongruente versus ausência de humor em uma propaganda e a variável dependente atitude do consumidor sobre a empresa. Neste sentido, constatou-se que as participantes que observaram a propaganda com humor incongruente obtiveram atitudes mais favoráveis sobre a empresa $(\mathrm{M}=6,19 ; \mathrm{DP}=0,91)$ quando comparadas às mulheres que avaliaram a propaganda sem humor $(\mathrm{M}=5,57 ; \mathrm{DP}=0,86)$. Desta forma, a hipótese $\mathbf{H 2 b}$ foi aceita.

O que se fez, neste estudo, foi seguir a recomendação de Spielmann (2014) em isolar um tipo de humor e verificar sua influência em contexto e audiência específicos - neste caso, as redes sociais e as mulheres respectivamente. É sabido, ainda, que a resolução da incongruência gera surpresa e descontração, sendo estas reações positivas elementos favoráveis à elaboração da atitude (Alden et al., 1993; Spielmann, 2014). Com base nisso, as hipóteses H2a e H2b foram testadas e confirmadas.

Analisando as diferenças entre o efeito do humor incongruente nas atitudes sobre a propaganda e nas atitudes sobre a empresa, é possível identificar que, em ambos os casos, as participantes responderam de forma mais positiva aos anúncios que continham o humor incongruente em comparação àquelas expostas ao anúncio sem humor. Há respaldo na literatura para estes achados.

Os efeitos do humor na propaganda são conhecidos, especialmente no que tange à formação de atitude do consumidor (Fazio et al., 1982; Lyttle, 2001; Ray \& Batra, 1983; Zhang, 1996). O avanço da tecnologia da informação e a consequente expansão da internet reforçou este efeito: mensagens divertidas são bem aceitas pelo público, gerando reações emocionais positivas capazes de orientarem suas atitudes, sejam elas em relação ao anúncio em si ou à empresa anunciante (Carrillat et al., 2014; Hahn et al., 2016). 
Para a hipótese $\mathrm{H} 2 \mathrm{c}$, há diferenças entre a presença de humor incongruente versus ausência de humor em uma propaganda e a variável dependente intenção de compra. Essa hipótese, H2c, também foi confirmada pelos resultados expostos na Tabela $6(\mathrm{~F}=125,402, \mathrm{p}<0,001)$. As Figuras 1 e 2 corroboram tal achado, já que as participantes que observaram a propaganda com humor incongruente revelaram maior intenção de compra $(\mathrm{M}=6,79 ; \mathrm{DP}=0,54)$ quando comparadas às que avaliaram a propaganda sem humor $(\mathrm{M}=6,02 ; \mathrm{DP}=0,58)$.

A confirmação da $\mathrm{H} 2 \mathrm{c}$ demonstrou que a propaganda com humor incongruente gera maior intenção de compra do que a propaganda sem humor. Ratifica-se, com isso, que a conexão estabelecida entre usuários de redes sociais e marcas que anunciam neste contexto promove a interação, articula o relacionamento entre as partes e constrói confiança na marca, contribuindo com a intenção de compra do consumidor (Dehghani \& Tumer, 2015; Duffett, 2015; Gunawan \& Huarng, 2015; Silva et al., 2017).

Para além do exposto, a literatura já reconhece o efeito do uso de humor em propagandas na intenção de compra (Lyttle, 2001; Smith \& Sherman, 1993), contudo, havia a necessidade de se explorar os efeitos das dimensões do humor de maneira isolada (Spielmann, 2014). Neste sentido, os resultados aqui engendrados, além de encontrarem subsídio na literatura visitada, confirmam que o uso do humor incongruente tem efeitos sobre a efetividade das propagandas no contexto das redes sociais.

\section{Discussão Geral}

Observa-se, diante das discussões acerca da confirmação das hipóteses, que a efetividade do humor nas propagandas, em termos de engajamento, atitudes e intenção de compra, também se confirma no contexto das redes sociais. Este resultado abre espaço acerca de temas emergentes na literatura de marketing.

O primeiro deles concerne ao domínio da propaganda. A expansão da internet e o alcance das redes sociais tiveram como consequência o refreamento das mídias tradicionais, tornando o ambiente virtual o novo cenário de comunicação entre indivíduos, instituições, marcas e empresas. De acordo com Duffett (2015), as redes sociais passam a fazer parte da estratégia global de marketing e das atividades das empresas, trazendo à baila urgência em se conhecer as ferramentas mais adequadas ao ambiente digital, de modo a assegurar a eficiência da comunicação com os consumidores.

Sob tal perspectiva, é preciso considerar a forma como as marcas e as redes sociais são percebidas por suas audiências, pois à medida que se aproximam do público, adquirem personalidade e o relacionamento adquire um caráter mais íntimo (Silva et al., 2017). Neste contexto, as marcas se aproximam dos clientes e, ao mesmo tempo em que têm acesso facilitado a informações, precisam cuidar da forma como dialogam com seus consumidores, do conteúdo de suas mensagens e da condução destes novos relacionamentos.

O humor incongruente pode ser um caminho para desenvolver estes relacionamentos. Foi Spielmann (2014) quem alertou sobre a necessidade de se estudar as dimensões de humor de maneira isolada. Neste tocante, os achados desta pesquisa reforçam que não é suficiente usar o humor na propaganda, sendo necessário escolher qual tipo de humor é o mais efetivo para cada público e adequar linguagem, imagens e contexto de maneira a se conquistar o engajamento do público, suas atitudes e intenção de compra.

Ainda, considerando que a concorrência é amplificada no cenário digital (Silva et al., 2017), os resultados aqui engendrados permitem dizer que propagandas sem conteúdo atrativo (no caso, sem humor), tendem a passar despercebidas, sendo as mensagens engraçadas, curiosas e inusitadas geradoras de emoções positivas, tornando-se capazes de conduzir comentários e compartilhamentos nas redes sociais. 
Na interpretação de Silva, Demo e Scussel (2017), compreender a dinâmica entre consumidores e marcas é um imperativo às empresas que, queiram ou não, fazem parte do contexto online. Dada a necessidade de se considerar a audiência para quem se destinam as mensagens (Spielmann, 2014) e a emergência de estudos sobre a mudança do comportamento feminino (Aillaud \& Piolat, 2012; Goldenberg \& Jablonski, 2011; Schwarz et al., 2015), surgem algumas reflexões.

É imprescindível que empresas, marcas e agências de publicidade busquem conhecer e discutam as novas facetas do público feminino decorrentes de movimentos como o feminismo, uma vez que a quebra de estereótipos femininos e masculinos têm impacto na forma como os indivíduos se colocam no mundo, como consomem e como interagem nas redes sociais. Este cenário coloca em evidência a necessidade de se fazer propaganda de forma diferente: os apelos tradicionalmente destinados a homens e mulheres já não têm o mesmo apelo, podendo ainda gerar repercussões negativas sobre a imagem de uma marca na internet. Haja vista a rapidez com que comentários e compartilhamentos acontecem, bem como as associações que vinculam as marcas ao seu comportamento online (Silva et al., 2017), o risco de um conteúdo inapropriado precisa ser estudado.

Destarte, os achados aqui discutidos apresentam um panorama acerca da efetividade das propagandas no contexto das redes sociais, colocando o humor como ponto de partida para chamar a atenção do público, em especial das mulheres, contribuindo para a formulação de suas atitudes, intenção de compra e, ainda, conquistando engajamento.

\section{Considerações Finais}

Este artigo concentrou-se em analisar o efeito das propagandas com humor incongruente no engajamento, nas atitudes e na intenção de compra de consumidoras brasileiras no contexto das redes sociais. O ponto de partida foi a necessidade de se investigar os efeitos de cada dimensão do humor, um recurso amplamente utilizado para sensibilizar consumidores, de maneira isolada. A dimensão escolhida foi o humor incongruente e o cenário da pesquisa foi o Facebook, rede social mais popular no Brasil e reconhecidamente um espaço de interação entre usuários e marcas.

Para mensurar a efetividade das propagandas com humor incongruente no Facebook, foram elaboradas hipóteses relativas ao engajamento, atitudes sobre a propaganda, atitudes sobre a marca e intenção de compra das consumidoras. Todas as hipóteses foram confirmadas, desvelando que o humor incongruente afeta a efetividade da propaganda no contexto das redes sociais, além de demonstrar que se trata de um apelo humorístico com efeitos positivos sobre o público feminino.

Concernente às contribuições deste trabalho, os achados confirmam que engajamento, atitudes e intenção de compra conformam importantes medidas da efetividade das propagandas no contexto virtual, um tema recente dado à evolução da tecnologia e que incita atenção da literatura. Há, aqui, pistas para o desenvolvimento de instrumentos capazes de mensurar os efeitos das propagandas no contexto das redes sociais: uma realidade que tende à expansão, cujas consequências para usuários, empresas e as próprias redes sociais ainda são desconhecidas.

Esta pesquisa é contributiva também no sentido de revelar novas facetas sobre a percepção das mulheres quanto a estímulos tradicionalmente destinados aos homens. Com a crescente quebra de estereótipos a respeito do comportamento feminino, faz-se necessário discutir os novos temas, referências e percepções que trazidos por tal mudança, especialmente no que concerne ao papel das marcas e das propagandas na construção de uma sociedade de consumo mais próxima da equidade de gênero.

No que tange às implicações gerenciais da pesquisa, evidencia-se as redes sociais como elementos fundamentais à tomada de decisão do consumidor. Isso evidencia não só o papel da internet como plataforma de interação entre empresas e usuários, mas a necessidade de presença online das marcas, da criação de conteúdo atrativo, de propagandas capazes de chamar atenção e de dialogar com

RAC, Rio de Janeiro, v. 23, n. 1, art. 1, pp. 1-22, janeiro/fevereiro, 2019, http://rac.anpad.org.br (co) EY 
o consumidor via redes sociais. Acredita-se, ainda, que os construtos engajamento, atitude e intenção de compra aqui analisados podem trazer pistas às empresas de como se relacionarem com seu público na internet. Trata-se de uma nova conjuntura, que demanda das marcas e empresas o desenho de novas estratégias capazes de alcançar seus públicos. Conforme exposto neste trabalho, propagandas divertidas, especialmente aquelas que recorrem ao humor incongruente, podem ser um ponto de partida.

Como limitações, tem-se a amostragem não probabilística e não generalizável para a população, restringindo-se a população do estudo a apenas mulheres usuárias do Facebook. Relata-se, ainda, a ausência de uma medida capaz de mensurar o engajamento entre empresas e consumidores no ambiente virtual. Neste estudo, recorreu-se às formas de interação propostas pelo próprio Facebook, o que indica que os resultados tecidos aqui são mais indicativos do que conclusivos. Contudo, tal limitação vem a configurar uma lacuna de pesquisa, reclamando estudos capazes de explicar como se dá o engajamento entre marcas e consumidores no ciberespaço, recorrendo a abordagens exploratórias capazes de encaminhar os pesquisadores a posterior construção de um instrumento que possa mensurar esta relação.

Para futuras investigações, sugere-se a aplicação deste experimento em outras redes sociais, de forma a conhecer a percepção do público em relação a diferentes plataformas, mas também uma análise comparativa das redes sociais e seu poder no que tange ao engajamento, às atitudes e à intenção de compra. Vislumbra-se, ainda, estudos com outras audiências, especialmente aquelas cujos comportamentos frente ao ambiente virtual diferem, como, por exemplo, os nativos digitais e os idosos. Por fim, recomenda-se a realização de trabalhos como este em um contexto longitudinal, com base em futuras tendências do ambiente virtual e novas perspectivas em comportamento do consumidor.

\section{Material Suplementar}

Todos os dados e materiais foram disponibilizados publicamente por meio da plataforma Mendeley e podem ser acessados em: Scussel, Fernanda (2018), "Dados do artigo "Humor Incongruente, Efetividade da Propaganda e as Mulheres: Um Experimento no Facebook"”, Data, v1http://dx.doi.org/10.17632/d6cgfnwt6r.1

\section{Contribuições}

$1^{\circ}$ autor: artigo proveniente de sua dissertação de mestrado, defendida no Programa de Pós-Graduação em Administração (PPGA/UFSC).

$2^{\circ}$ autor: orientador da $1^{\circ}$ autora; auxiliou em todo o trabalho, desde a dissertação, até na sua transformação para artigo.

$3^{\circ}$ autor: realizou melhorias e adequações em todo o trabalho (introdução, incremento teórico, etc) para a publicação na revista, bem como transformou a dissertação em formato de artigo.

$4^{\circ}$ autor: auxiliou nas análises estatísticas, na revisão de todo o artigo e acompanhou o trabalho da primeira autora nos exames de qualificação e defesa de sua dissertação.

\section{Referências}

Aillaud, M., \& Piolat, A. (2012). Influence of gender on judgment of dark and nondark humor. Individual Differences Research, 10(4), 211-222.

Alden, D. L., Hoyer, W. D., \& Lee, C. (1993). Identifying global and culture-specific dimensions of humor in advertising: A multinational analysis. The Journal of Marketing, 57(2), 64-75. http://doi.org/10.2307/1252027

RAC, Rio de Janeiro, v. 23, n. 1, art. 1, pp. 1-22, janeiro/fevereiro, 2019, http://rac.anpad.org.br (co)) 
Alden, D. L., Mukherjee, A., \& Hoyer, W. D. (2000). The effects of incongruity, surprise and positive moderators on perceived humor in television advertising. Journal of Advertising, 29(2), 1-15. https://doi.org/10.1080/00913367.2000.10673605

Alexander, M. W., \& Judd, B. (1978). Do nudes in ads enhance brand recall. Journal of Advertising Research, 18(1), 47-50. https://doi.org/10.1177/205157070702200401

Al-Saggaf, Y. (2011). Saudi females on Facebook: An ethnographic study. International Journal of Emerging Technologies and Society, 9(1), 1-19.

Al-Saggaf, Y., \& Nielsen, S. (2014). Self-disclosure on Facebook among female users and its relationship to feelings of loneliness. Computers in Human Behavior, 36, 460-468. https://doi.org/10.1016/j.chb.2014.04.014

Araújo, C. M. B., \& Loureiro, S. M. C. (2014). O efeito da norma subjetiva, percepção de controlo, atitude e experiência passada na intenção de compra de marcas de roupa de luxo no Brasil [Edição Especial]. Tourism \& Management Studies, 10, 103-110.

Ashley, C., \& Tuten, T. (2015). Creative strategies in social media marketing: An exploratory study of branded social content and consumer engagement. Psychology \& Marketing, 32(1), 15-27. https://doi.org/10.1002/mar.20761

Barker, V., \& Ota, H. (2011). Mixi diary versus Facebook photos: Social networking site use among Japanese and Caucasian American females. Journal of Intercultural Communication Research, 40(1), 39-63. https://doi.org/10.1080/17475759.2011.558321

Batra, R., \& Keller, K. L. (2016). Integrating marketing communications: New findings, new lessons, and new ideas. Journal of Marketing, 80(6), 122-145. https://doi.org/10.1509/jm.15.0419

Beard, F. K. (2008). Humor in the advertising business: Theory, practice, and wit. Plymouth, UK: Rowman \& Littlefield Publishers.

Borges, L. A. D. S., Carvalho, D. T. D., \& Miranda, C. D. S. (2016). Antecedentes da intenção de compra de marcas próprias: Um estudo no mercado emergente. Revista de Administração de Empresas, 56(6), 611-625. http://doi.org/10.1590/s0034-759020160604

Brodie, R. J., Hollebeek, L. D., Jurić, B., \& Ilić, A. (2011). Customer engagement: Conceptual domain, fundamental propositions, and implications for research. Journal of Service Research, 14(3), 252-271. https://doi.org/10.1177/1094670511411703

Bues, M., Steiner, M., Stafflage, M., \& Krafft, M. (2017). How mobile in-store advertising influences purchase intention: Value drivers and mediating effects from a consumer perspective. Psychology \& Marketing, 34(2), 157-174. https://doi.org/10.1002/mar.20981

Carrillat, F. A., D'Astous, A., \& Grégoire, E. M. (2014). Leveraging social media to enhance recruitment effectiveness: A Facebook experiment. Internet Research, 24(4), 474-495. https://doi.org/10.1108/IntR-07-2013-0142

Catanescu, C., \& Tom, G. (2001). Types of humor in television and magazine advertising. Review of Business, 22(1/2), 92.

Cifuentes, C. M. (2005). Tipos de humor en la publicidad impresa en Colombia. Diversitas: Perspectivas en Psicología, 1(1), 31-45.

Crawford, H. J., \& Gregory, G. D. (2015). Humorous advertising that travels: A review and call for research. Journal of Business Research, 68(3), 569-577. https://doi.org/10.1016/j.jbusres.2014.09.005 
Dehghani, M., \& Tumer, M. (2015). A research on effectiveness of Facebook advertising on enhancing purchase intention of consumers. Computers in Human Behavior, 49, 597-600. https://doi.org/10.1016/j.chb.2015.03.051

Doorn, J. van, Lemon, K. N., Mittal, V., Nass, S., Pick, D., Pirner, P., \& Verhoef, P. C. (2010). Customer engagement behavior: Theoretical foundations and research directions. Journal of Service Research, 13(3), 253-266. https://doi.org/10.1177/1094670510375599

Duffett, R. G. (2015). Facebook advertising's influence on intention-to-purchase and purchase amongst Millennials. Internet Research, 25(4), 498-526. https://doi.org/10.1108/IntR-012014-0020

Fazio, R. H., Chen, J. M., McDonel, E. C., \& Sherman, S. J. (1982). Attitude accessibility, attitudebehavior consistency, and the strength of the object-evaluation association. Journal of Experimental Social Psychology, 18(4), 339-357. https://doi.org/10.1016/0022-1031(82)900580

Fedrizzi, A. (2003). O humor abre corações e bolsos. Rio de Janeiro: Campus.

Garcia, G. M., \& Santos, C. P. (2011). O impacto das características pessoais na intenção de compra pela internet e o papel de mediação da familiaridade e da atitude frente à compra pela internet. Revista de Administração Mackenzie, 12(5), 151-181. http://doi.org/10.1590/S167869712011000500007

Goldenberg, M., \& Jablonski, B. (2011). O gênero da risada. Psicologia Clínica, 23(2), 17-29. http://doi.org/10.1590/S0103-56652011000200002

Gunawan, D. D., \& Huarng, K. H. (2015). Viral effects of social network and media on consumers' purchase intention. Journal of Business Research, 68(11), 2237-2241. https://doi.org/10.1016/j.jbusres.2015.06.004

Hair, J. F., Black, W. C., Babin, B. J., Anderson, R. E., \& Tatham, R. L. (2009). Análise multivariada de dados (6th ed.). Porto Alegre: Bookman.

Hahn, I. S., Scherer, F. L., Basso, K., \& Santos, M. B. (2016). Consumer trust in and emotional response to advertisements on social media and their influence on brand evaluation. Brazilian Business Review, 13(4), 49- 71. https://doi.org/10.15728/bbr.2016.13.4.3

Hegarty, J. (2003). Quando eles não estão sorrindo. In A. Fedrizzi (Org.), O humor abre corações e bolsos (pp. 70-74). Rio de Janeiro: Campus.

Henthorne, T. L., \& LaTour, M. S. (1995). A model to explore the ethics of erotic stimuli in print advertising. Journal of Business Ethics, 14(7), 561-569. https://doi.org/10.1007/BF00871984

Hirsch, G. (2017). Humor appreciation in the digital era. Lingua, 197, 123-140. https://doi.org/10.1016/j.lingua.2017.06.016

Ifezue, A. N. (2010). What makes an effective advertising for a man or a woman?. Journal of Communication, 1(1), 13-18.

Kaplan, A. M., \& Haenlein, M. (2010). Users of the world, unite! The challenges and opportunities of Social Media. Business Horizons, 53(1), 59-68. https://doi.org/10.1016/j.bushor.2009.09.003

Kellaris, J. J., \& Cline, T. W. (2007). Humor and ad memorability: On the contributions of humor expectancy, relevancy, and need for humor. Psychology \& Marketing, 24(6), 497-509. https://doi.org/10.1002/mar.20170 
Kleineberg, K. K., \& Boguñá, M. (2016). Competition between global and local online social networks. Scientific Reports, 6, 25116. https://doi.org/10.1038/srep25116

Krishnan, H. S., \& Chakravarti, D. (2003). A process analysis of the effects of humorous advertising executions on brand claims memory. Journal of Consumer Psychology, 13(3), 230-245. https://doi.org/10.1207/S15327663JCP1303_05

Lamberton, C., \& Stephen, A. T. (2016). A thematic exploration of digital, social media, and mobile marketing: Research evolution from 2000 to 2015 and an agenda for future inquiry. Journal of Marketing, 80(6), 146-172. https://doi.org/10.1509/jm.15.0415

LaTour, M. S., \& Henthorne, T. L. (1993). Female nudity: Attitudes towards the ad and the brand, and implications for advertising strategy. Journal of Consumer Marketing, 10(3), 25-32. https://doi.org/10.1108/07363769310041956

LaTour, M. S., \& Henthorne, T. L. (1994). Ethical judgments of sexual appeals in print advertising. Journal of Advertising, 23(3), 81-90. https://doi.org/10.1080/00913367.1994.10673453

Logan, K., Bright, L. F., \& Gangadharbatla, H. (2012). Facebook versus television: advertising value perceptions among females. Journal of Research in Interactive Marketing, 6(3), 164-179. https://doi.org/10.1108/17505931211274651

Lyttle, J. (2001). The effectiveness of humor in persuasion: The case of business ethics training. The Journal of General Psychology, 128(2), 206-216. https://doi.org/10.1080/00221300109598908

MacKenzie, S. B., \& Lutz, R. J. (1989). An empirical examination of the structural antecedents of attitude toward the ad in an advertising pretesting context. The Journal of Marketing, 53(2), 4865. http://doi.org/10.2307/1251413

Martin, R. A. (2007). The psychology of humor: An integrative approach. Burlington: Elseiver Academic Press.

Moalla, A. (2014). Incongruity in the generation and perception of humor on Facebook in the aftermath of the Tunisian Revolution. Journal of Pragmatics, 75, 44-52. https://doi.org/10.1016/j.pragma.2014.10.008

Moalla, A. (2015). Incongruity in the generation and perception of humor on Facebook in the aftermath of the Tunisian revolution. Journal of Pragmatics, 75, 44-52. https://doi.org/10.1016/j.pragma.2014.10.008

Nelson-Field, K., Riebe, E., \& Sharp, B. (2012). What's not to "like?": Can a Facebook fan base give a brand the advertising reach it needs?. Journal of Advertising Research, 52(2), 262-269. https://doi.org/10.2501/JAR-52-2-262-269

Neudecker, N., Esch, F. R., Schaefers, T., \& Valussi, S. (2014). Message reframing in advertising. Psychology \& Marketing, 31(11), 946-957. https://doi.org/10.1002/mar.20745

Oliveira, F. (2018). Facebook chega a 127 milhões de usuários mensais no Brasil. Recuperado em 20 de setembro, 2018, de https://www1.folha.uol.com.br/tec/2018/07/facebook-chega-a-127milhoes-de-usuarios-mensais-no-brasil.shtml

Patino, A., Pitta, D. A., \& Quinones, R. (2012). Social media's emerging importance in market $\begin{array}{llll}\text { research. Journal of } \quad \text { Consumer } & \text { 233-237. }\end{array}$ https://doi.org/10.1108/07363761211221800

Petroll, M. M. (2007) Apelo sexual na propaganda: um experimento em mídia impressa (Dissertação de mestrado). Universidade Federal do Rio Grande do Sul, Porto Alegre, RS, Brasil. 
Petroll, M. M., \& Rossi, C. A. V. (2008). Apelo sexual na propaganda e seus efeitos sobre o consumidor: Um experimento em mídia impressa. Revista de Administração Eletrônica, 1(2), 1$22 . \quad$ Recuperado de https://www.researchgate.net/profile/Carlos_Rossi5/publication/266875892_Apelo_sexual_na_ propaganda_e_seus_efeitos_sobre_o_consumidor_um_experimento_em_midia_impressa/links/ 54b665b20cf24eb34f6d159a/Apelo-sexual-na-propaganda-e-seus-efeitos-sobre-o-consumidorum-experimento-em-midia-impressa.pdf

Rangel, N. S., Netto, Carneiro, T. C. J., de Oliveira, M. P. V., \& Monteiro, R. A. (2016). O que se deve levar em conta ao realizar análises de consumo por meio de publicações no Facebook?. Brazilian Business Review, 13(4), 1-24. http://doi.org/10.15728/bbr.2016.13.4.1

Ray, M., \& Batra, R. (1983) Emotion and persuasion in advertising: What we do and don't know about affect. Advances in Consumer Research, 10, 24-38.

Selmi, P. (2018). Mesmo com imagem abalada, lucro do Facebook cresce $63 \%$ no $1^{\circ}$ tri. Recuperado em 20 de setembro, 2018, de https://www.valor.com.br/empresas/5483161/mesmo-comimagem-abalada-lucro-do-facebook-cresce-63-no-1-tri

Shabbir, H., \& Thwaites, D. (2007). The use of humor to mask deceptive advertising: It's no laughing matter. Journal of Advertising, 36(2), 75-85. http://doi.org/10.2753/JOA0091-3367360205

Schwarz, U., Hoffmann, S., \& Hutter, K. (2015). Do men and women laugh about different types of humor? A comparison of satire, sentimental comedy, and comic wit in print ads. Journal of Current Issues \& Research in Advertising, 36(1), 70-87. https://doi.org/10.1080/10641734.2014.912599

Silva, T. L., Demo, G., \& Scussel, F. B. C. (2017) Credibilidade, audácia e alegria: Personalidades de marca que conectam os usuários às redes sociais. Anais do Seminários em Administração. São Paulo, SP, Brasil, 20.

Simpson, P. M., Horton, S., \& Brown, G. (1996). Male nudity in advertisements: A modified replication and extension of gender and product effects. Journal of the Academy of Marketing Science, 24(3), 257-262. https://doi.org/10.1177/0092070396243006

Smith, R. B., \& Sherman, E. (1993). Effects of store image and mood on consumer behavior: A theoretical and empirical analysis. ACR North American Advances, 20, 631. https://doi.org/10.5539/ijms.v7n2p35

Souza, B. B. P. (2012). Antecedentes e dimensões do engajamento dos usuários de redes sociais: Um estudo com o facebook (Tese de doutorado). Universidade Federal de Minas Gerais, Belo Horizonte, MG, Brasil.

Spielmann, N. (2014). How funny was that? Uncovering humor mechanisms. European Journal of Marketing, 48(9/10), 1892-1910. https://doi.org/10.1108/EJM-07-2012-0393

Stathopoulou, A., Borel, L., Christodoulides, G., \& West, D. (2017). Consumer branded\# hashtag engagement: can creativity in TV advertising influence hashtag engagement?. Psychology \& Marketing, 34(4), 448-462. https://doi.org/10.1002/mar.20999

Strick, M., Holland, R. W., Baaren, R. B. van, \& Knippenberg, A. van (2012). Those who laugh are defenseless: How humor breaks resistance to influence. Journal of Experimental Psychology: Applied, 18(2), 213-231. https://doi.org/10.1037/a0028534

Terra, C. F. (2010). Usuário-mídia: A relação entre a comunicação organizacional e o conteúdo gerado pelo internauta nas mídias sociais (Tese de doutorado). Universidade de São Paulo, São Paulo, SP, Brasil. 
Vilaverde, C. (2016). As 12 redes sociais com mais mulheres. Recuperado em 20 de setembro, 2018, de https://super.abril.com.br/blog/superlistas/as-12-redes-sociais-com-mais-mulheres/

Wolny, J., \& Mueller, C. (2013). Analysis of fashion consumers' motives to engage in electronic word-of-mouth communication through social media platforms. Journal of Marketing Management, 29(5/6), 562-583. https://doi.org/10.1080/0267257X.2013.778324

Zepeda, A. V., Franco, D. A. H., \& Preciado, O. A. P. (2014). El miedo como estrategia "ganadora": el caso de la elección presidencial en México, 2006. Revista de Ciencias Sociales, 3(145), 133 146.

Zhang, Y. (1996). Responses to humorous advertising: The moderating effect of need for cognition. Journal of Advertising, 25(1), 15-32. https://doi.org/10.1080/00913367.1996.10673493

\section{Autores}

Luciana Ribeiro

Campus Reitor João David Ferreira Lima, 88040-900, Florianópolis, SC, Brasil.

E-mail: lucianaribeirov@gmail.com

Martin de La Martinière Petroll

Campus Reitor João David Ferreira Lima, 88040-900, Florianópolis, SC, Brasil.

E-mail: martin.petroll@ufsc.br

Fernanda Scussel

Campus Reitor João David Ferreira Lima, 88040-900, Florianópolis, SC, Brasil.

E-mail: fbcardoso@gmail.com

Claudio Damacena

Av. Ipiranga, 6681, Edifício 50, sala 1101.17, 90619-900, Porto Alegre, RS, Brasil.

E-mail: claudio.damacena@pucrs.br 